\title{
Complementary Therapies for Treating Survivors of Torture
}

\author{
Claudia María Vargas, Deborah O’Rourke, and Malshid Esfandiari
}

\begin{abstract}
The long-term consequences of torture are complex, multidimensional, and pervasive. Torture leaves indelible scars in the mind, body, and cultural world of survivors, compromising their health and well-being. A clearer understanding of biological, psychological, and socio-cultural mechanisms underlying these difficulties is emerging. Research findings on pain are relevant for those suffering from post-traumatic stress disorder (PTSD) and its associated chronic pain. Rehabilitation programs require crossdisciplinary knowledge and expertise, including of complementary therapies. This article explores the use of complementary therapies in which psychotherapy, in concert with either physiotherapy or bodywork, is offered. Case studies illustrate its application and potential benefits. The clinical experience in controlled circumstances suggests the thesis that complementary therapies advance the psychological and physical healing process.
\end{abstract}

\section{Résumé}

Les conséquences à long terme de la torture sont complexes, multidimensionnelles et envahissantes. La torture laisse des cicatrices indélébiles sur la psyché, le corps physique et l'espace culturel des rescapés, compromettant leur santé et leur bien-être. Une meilleure compréhension des mécanismes biologiques, psychologiques et socioculturels sous-tendant ces difficultés commence à prendre forme. Les résultats de la recherche sur la douleur sont pertinents pour ceux qui souffrent du syndrome de stress post-traumatique (SSPT) et des douleurs chroniques associées. Les programmes de réhabilitation requièrent des connaissances spécialisées multidisciplinaires, y compris une connaissance des méthodes thérapeutiques complé- mentaires. Cet article examine l'usage de méthodes thérapeutiques complémentaires où la psychothérapie est offerte de pair avec soit la physiothérapie ou des approches corporelles ('bodywork'). Des études de cas démontrent ses domaines d'application et ses avantages potentiels. L'expérience clinique, menée dans des conditions contrôlées, suggère l'hypothèse que les approches complémentaires et parallèles en santé ont pour effet de promouvoir le processus de guérison psychologique et physique.

$\mathrm{W}$ hen refugees arrive in their host country, it is a relief from persecution, an end to flight, and the beginning of a new life, though the baggage of exile accompanies them. For those who endured imprisonment, violence, or torture, the psychological and physical sequelae are compounded by cultural bereavement, the disruption of cultural and familial connections and supports the loss of identity, status, loved ones, structures of meaning, symbols, heritage, language, and traditions. ${ }^{1}$ These new arrivals have many needs and may require help dealing with issues that could stand in the way of their emotional and physical well-being. Effective assistance for these challenges requires a careful consideration of a cross-disciplinary approach in which a variety of therapeutic interventions can work together to improve health.

Although traumatic episodes leave indelible scars in the mind, body, and spirit of a person, recognition of its effect as post-traumatic stress disorder (PTSD) dates back only two decades. Since then, research on PTSD has profoundly influenced how it is conceptualized and treated; much has been learned about its complex biological, psychological, and social processes. ${ }^{2}$ A parallel exists between the historic difficulties in obtaining recognition for PTSD and gaining recognition of the effects of pain by clinicians and re- 
searchers. Consequently, the short-term effects of unrelieved pain associated with trauma, injury, and illness are well known, but understanding of the long-term deleterious effects of pain is more recent. Research in the past two decades has radically altered knowledge and attitudes regarding the health risks associated with exposure to severe, persistent physical pain.

These issues are relevant because significant numbers of refugees are survivors of torture. Torture, according to the International Rehabilitation Council for Torture Victims (IRCT), is "the intentional infliction of severe pain or suffering for a specific purpose." ${ }^{3}$ While the prevalence of torture is uncertain, some studies estimate that 5 to 35 per cent of refugees suffered torture in their homelands, ${ }^{4}$ while similar surveys in other countries estimate from 5 to 30 per cent. ${ }^{5} \mathrm{~A}$ growing medical literature documents the physical problems confronting survivors of torture - chronic pain with symptoms of diffuse and persistent musculoskeletal pain and other types of chronic pain. ${ }^{6}$ These were considered psychosomatic in origin due to significant discrepancies between subjective reports of pain and positive physical findings. ${ }^{7}$

This article proposes consideration of an integrated approach to treating survivors of torture - psychotherapy concurrently with physiotherapy or bodywork - after ruling out any medical problem, as practiced at the Vancouver Association for Survivors of Torture (VAST). The underlying assumption is that, when treating survivors of torture who are suffering from chronic pain, there is a need to deal with psychological issues as much as physical pain. The psychotherapies represent various schools of psychology: psychoanalytic, behavioural, cognitive, and existentialist. The bodywork is also diverse in technique and cultural representation. The integrated approach intends to soothe pain or desensitize physiological, cognitive, and affective structures affecting chronic physical pain and PTSD symptoms. Case studies illustrate its potential benefits.

The discussion is organized in three parts. Part one provides an overview of the pain literature. Part two introduces various forms of bodywork. Part three explains implementation of the complementary approach. The last analyzes how complementary therapies work. The emerging thesis is that physical and psychological therapies, in concert, can attenuate the indelible scars of torture by sensitizing the body to healing touch, leading to a faster path of recovery.

\section{Physiological Consequences of Torture}

The assumption that physical pain, unexplained by medical or physical findings, is psychosomatic in origin has been long-standing and pervasive as was pain reported by survivors of torture attributed to psychological trauma. Of course, not all health workers made this assumption. In the early 1950s, Dr. Pappworth, whose work is described in $A$ Good Listener, ${ }^{8}$ acknowledged the increased propensity of torture survivors to suffer from pain. Investigations of PTSD have also elucidated how trauma affects neurobiology through complex psychobiological mechanisms. ${ }^{9}$ Similarly, recent pain research explains how exposure to severe and prolonged pain triggers a cascade of neurobiological events that can result in long-term cellular changes and chronic pain states. ${ }^{10}$

The capacity to perceive and respond to pain is a fundamental survival skill. Pain serves an important protective function by alerting individuals to injury, illness, and disease states. ${ }^{11}$ Paradoxically, while physiological pain is adaptive and contributes to general health and well-being, unrelieved and persistent pain is known to impair health, limit functional capabilities, and compromise quality of life. ${ }^{12}$ Because survivors of torture have endured severe and prolonged pain, they are at a high risk for development of chronic pain and associated health and functional problems.

Pain is a complex, multi-dimensional topic, requiring the cross-disciplinary resources of scientists and clinicians. Although recent research has resulted in remarkable molecular level discoveries, pain is not merely a neurobiological event. Psychological and social factors profoundly influence the experience of pain, consequently, current conceptual models embrace a biobehavioural or biopsychosocial framework. ${ }^{13}$ These integrated conceptual models acknowledge that pain perceptions evolve over time and are influenced by prior pain experience as well as psychological, social, and environmental factors.

A discussion of chronic pain requires a brief overview of pain definitions, concepts, and theories. The International Association for the Study of Pain (IASP) defines pain as "an unpleasant sensory and emotional experience associated with actual and potential tissue damage." ${ }^{14}$ It has been described in terms of a "pain episode" composed of four components: nociception, pain, pain behaviour, and suffering. ${ }^{15}$ "Nociception" is defined as a physiological signal that alerts the nervous system to a noxious or tissue damaging stimulus. ${ }^{16}$ This is distinguished from "pain," defined as the sensory perception of the nociceptive stimulus. ${ }^{17}$ The pain episode may be associated with suffering, the affective reaction to pain, and pain behaviours, or observable behavioural actions in response to pain. ${ }^{18}$

The experience of pain is also defined in temporal terms distinguishing chronic pain from acute pain. Acute pain is defined as limited in duration, recent in onset, with an identified cause such as trauma, surgery, or disease. In contrast, chronic pain persists and remains long after healing. ${ }^{19}$ Clinically, the time associated with the development 
of chronic pain may be less than one month or more than six months. ${ }^{20}$

According to the traditional specificity theory, pain was predicted to be proportional to the extent of tissue damage and resolved with healing. ${ }^{21}$ In 1965, Wall and Melzack introduced the gate control theory of pain, which challenged conventional thinking and suggested that the nociceptive transmission could be amplified or inhibited at the level of the spinal cord by descending control from the brain..$^{22}$ This theory, however, did not fully explain the symptoms associated with chronic pain. ${ }^{23}$ During the 1980s, research demonstrated neuronal plasticity or "an alteration in pain signal processing in the nervous system in response to a painful stimulus or experience." ${ }^{24}$

The concept of plasticity is central to current theories of pain, supported by evidence that neurons in the brain and spinal cord change in structure, function, or neurochemistry in response to severe and prolonged noxious events. ${ }^{25}$ These changes are associated with the transition of acute pain to chronic pain. ${ }^{26}$ Persistent pain over periods as short as hours or days can trigger enduring changes in the central nervous system, amplifying and prolonging pain after the event. ${ }^{27}$ Investigations of the mechanisms responsible for these changes have revealed a great deal about chronic pain.

Chronic pain states are characterized by hyperalgesia, increased sensitivity to painful stimuli; allodynia, pain associated with a non-noxious stimulus; and hyperesthesia, increased sensitivity to sensory stimuli. ${ }^{28}$ Central sensitization is believed to contribute to the development of hyperalgesia and allodynia. ${ }^{29}$ The neural mechanisms underlying central sensitization are complex and illustrate both modulation and modification forms of neuronal plasticity. Central sensitization is characterized by an increase in spontaneous neuronal activity, decreased threshold for firing, an increase in magnitude and duration of firing, and expanded peripheral receptive fields for dorsal horn neurons. ${ }^{30}$ Specific neuronal modifications include alterations in gene regulation and the altered expression of specific neurotransmitters, changes in the structure of proteins, and alterations in neuron cell membrane structure and function. ${ }^{31}$ In other words, chronic pain is associated with neuronal changes through various mechanisms.

Pain perception can be inhibited and magnified. Current understanding of inhibitory mechanisms builds upon the gate control theory of pain, which predicted pain could be diminished or blocked at the level of the spinal cord through activation of cognitive and affective pathways in the brain. ${ }^{32}$ These descending pathways provide the mechanisms for cognitive, attentional, and emotional strategies to alter pain perception at the spinal cord level. ${ }^{33}$ The neural mechanisms involved include the actions of various inhibi- tory neurotransmitters ${ }^{34}$ from higher centres in the brain ${ }^{35}$ that attenuate nociceptive signals. ${ }^{36}$ However, in chronic pain states, normal inhibitory control mechanisms are disrupted.

Current pain research and concepts are important to consider for survivors of torture. Clinicians must recognize the neurobiological consequences of unrelieved acute pain inflicted through inhumane torture practices. ${ }^{37}$ Though neurobiological processes underlying chronic pain are complex, they need to be considered in order to gain a greater understanding of why management of chronic pain is so challenging. From an applied perspective, current pain theories and concepts provide a framework for physiological, cognitive, and behavioural approaches used in pain management to treat survivors of torture. Treatments have included psychological, medical, surgical, or pharmacological therapies. ${ }^{38}$ Recently, other types of therapies have been introduced such as physiotherapy. ${ }^{39}$ Less known approaches today include the use of complementary and alternative medicine (CAM).

\section{Complementary Therapies}

When a person is so injured emotionally and physically, a single clinical approach may not fully address his or her physiological and psychological challenges. ${ }^{40}$ The process at VAST begins with an intake interview in which the needs of a survivor - psychological, emotional, physiological, medical, or related to resettlement - are assessed and prioritized. This approach first screens for possible physical injuries such as fractures, traumatic brain injury (TBI), ${ }^{41}$ illnesses, diseases, or other pathologies needing medical care. During intake, however, a client rarely expresses physical pain. Pain issues are often identified later on, perhaps in psychotherapy, in medical treatment, or in settlement assistance.

The clinician must be alert to the person's sensitivities to touch when bodywork is offered, based on cultural, religious, gender, or personal preference. The clinician also considers the most appropriate bodywork for the survivor. A person sensitive to touch may state quite plainly: "I don't want to take my clothes off," "I don't want someone else to see my torture scars," "My religion does not permit physical touch." In other instances, the survivor may not be this direct, may say nothing or accept to undergo the treatment.

\section{Conventional Physiotherapy}

The World Confederation for Physical Therapy (WCPT) encourages high professional standards through education, clinical practice, and research. ${ }^{42}$ In 1995 , the $13^{\text {th }}$ General Meeting of the WCPT adopted a Declaration of Principles on Torture, including statements underscoring the ethical imperative of physiotherapists to ease distress. As emphati- 
cally, it prohibits physiotherapists from engaging in or condoning torture. The International Rehabilitation Council for Torture Victims (IRCT) in Denmark has demonstrated exemplary leadership in disseminating information about rehabilitation and physiotherapy for torture survivors. ${ }^{43}$

Conceptually, physical therapy assessment and intervention usually reflects a four-level disablement framework: pathology; changes in body structure or function; difficulties performing self-care activities; and societal level disadvantage. ${ }^{44}$ The World Health Organization (WHO) International Classification of Functioning, Disability and Health (ICF) uses the terms "impairment," "activity," and "participation" to define problems in body structure or function, person level functioning, and societal or life situation issues, respectively. ${ }^{45}$

The focus of physiotherapy for survivors of torture was initially at the impairment level with the goal of restoring body structure and function. ${ }^{46}$ The treatment of specific muscle, joint, and movement problems was intended to alleviate pain and functional problems, but often the pain was unchanged. ${ }^{47}$ Current models of physiotherapy assume that survivors of torture have chronic pain, and treatment approaches mirror interventions for other groups who experience chronic pain. This acknowledges the complex and indelible changes in neurobiology associated with chronic pain and shifts the focus of physiotherapy away from impairment to activity and participation level interventions. "The [field of] physiotherapy has therefore changed and is now emphasizing active training, the main purpose being to stimulate the survivor of torture to live an active life despite pain and limitation of physical function." ${ }^{38}$ Physiotherapy specifically includes education, a promotion of functional capabilities through an appropriate exercise program, use of assistive devices as required, and relaxation and body awareness training. Equally important is the promotion of effective self-management of pain. ${ }^{49}$ This approach is consistent with current biopsychosocial models of chronic pain management for other groups, though physiotherapy is just one of many disciplines involved in caring for survivors of torture and their families.

\section{Bodywork Therapies}

Integrating psychotherapy with bodywork, or hand healing, presents a range of therapeutic alternatives. Bodywork, including physiotherapy, generally falls under three major approaches: (a) bodywork that involves manipulation of the body or direct touch, (b) bodywork that involves no touch or manipulation of the body, and (c) bodywork through soft touch of the body. VAST offers all three types.

The first category of bodywork encompasses various types in which there is direct manipulation of the body through deep muscle massage or heavy manipulation. Those practiced at VAST are: (1) neurological organizational technique (NOT); (2) Breema; (3) shiatsu; (4) massage therapy; (5) muscle response testing or applied kinesiology; (6) Hellerwork; (7) acupuncture; and (8) Tui Na Chinese medical massage. Breema, Kurdish in origin, and NOT are similar in that both involve heavy touch and pulling. Shiatsu combines the use of direct work and autosuggestive commands to the body. A more common practice in North America, massage therapy generally uses heavy massage of various areas of the body, though it may use a combination of heavy and soft touch. Muscle response testing or applied kineseology, established by Dr. George Goodheart, Jr., a chiropractor, is based on testing the strength or weakness of a particular muscle by touching pertinent points to make corrections, whether physical, mental, or emotional in origin. Hellerwork involves deep touch, but is limited to the fascia of the body. To facilitate motion restricted by collapsed layers of fascia or connective tissue, pressure on the muscles is exerted by using the fingers, knuckles, elbows, and arms. Because of the deep pressure, interaction between the practitioner and the patient is essential to signal potential painful or sore spots.

Anchored in ancient Chinese medicine, acupuncture requires inserting needles, for a few seconds or as long as half hour, to certain regions of the body to foster a balance of energy or the yin and yang. Though there is a risk of complications, ${ }^{50}$ its effectiveness has been documented in the treatment of certain conditions, narcotic withdrawal, pain, anxiety, and spastic muscle in children with cerebral palsy. ${ }^{51}$ Tui $\mathrm{Na}$ (push pull) Chinese medical massage, originating in Chinese traditional medicine dating back a couple of thousand years, uses the hands instead of needles to harmonize the chi or energy of the body; it is considered the grandparent of Shiatsu. "Tui Na operates from a system of four basic hand styles and is used to release spasms, increase circulation, and help prevent or reduce adhesion." ${ }^{2}$

The second category of bodywork departs significantly from the other two in that the body is not touched or manipulated in any way. Among the repertoire available, only reiki is practiced at VAST. Based on the concept of life energy, reiki seeks to capture what its practitioners refer to as the spiritual dimension of the soul and its universal intelligence. Originated in Japan by Dr. Usi in 1914, reiki only requires placing the hands above the injured or stressed area of a person to allow a transmission of energy.

The third type of bodywork resembles the first in that there is contact with the body of the patient, but differs in that the touch and manipulation are distinctly soft. Practitioners at VAST use: (1) the Rosen Method; (2) the Alexander Technique; (3) Bio-Energetics; and (4) craniosacral therapy. 
Marion Rosen originated the Rosen Method, characterized by stretching exercises and gentle body movements. "Using hands that listen rather than manipulate, the practitioner focuses on chronic muscle tension" as the bodyworker uses words to alert the patient to "unconscious muscle tension." ${ }^{33}$ Its uniqueness is based on a gentle but direct touch as the bodyworker is guided by changes in the breathing as barometers of internal relaxation or lack thereof.

The Alexander Technique, soft touch in nature, is grounded in the concept of unlearning habits that create muscular tension throughout the body. ${ }^{54}$ Practitioners contend that a patient, while learning a new "sensation, a new feeling" by increasing self-awareness about posture, balance, breathing, and coordination of movements, can release strain caused by everyday activities. "It can be applied while lying down, standing, walking, lifting, and other daily activities" 55 by focusing on the head and spine relationship to foster balance. Bio-Energetics, on the other hand, uses a biotensor, an instrument that detects different vibrations indicative of imbalance. A school of therapy, Bio-Energetics was the result of the collaboration between Eva Pierrakos and Dr. John Pierrakos, a psychiatrist. They argue that the biotensor, playing a dual role, is used to "add healing vibrations and loosen up energetic blockages." ${ }^{\prime 6}$

Last, craniosacral therapy operates on the principle of promoting healthy functioning of the central nervous system by activating the fluid system that nurtures it. ${ }^{57}$ Through gentle motions on a patient who lies comfortably and fully clothed on a table, the practitioner applies gentle pressure to activate the body's self-corrective ability.

Once therapy begins, the bodyworker particularly needs to be cautious abaut the possibility of flashbacks or hyperarousal in the session. Thus, it is important to have a psychotherapist prepared to intervene, if and when necessary.

\section{The Practice of Complementary Therapies}

A person's circumstances guide the decision as to which particular service he or she needs. Initially, the intake staff performs a basic screening to identify the most pressing mental and physical health needs. It is critical at this point to pay close attention to the survivor's emotions. When appropriate, the second step is to refer the person to a physician to assess the need for antidepressants to help with sleep disorders, to smooth out the affect, or medications to treat chronic pain, if present. Thereafter, the clinical coordinator assesses what could be a compatible match among the client, the bodyworker, and the psychotherapist. The cases below illustrate this sensitive interaction.

Case 1. The initial contact by a male survivor was based on the need for legal advocacy regarding asylum status. In the intake process, it was determined that this man needed psychotherapy immediately due to extensive and intensive symptoms of PTSD, specifically, sleep difficulties, nightmares, anxiety, depression, isolation, flashbacks, and fear. Later, bodywork was initiated when it became apparent that he had a great deal of physical pain and tension. Meantime, he was prescribed antidepressants.

Because he was particularly sensitive to touch, the Rosen Method, involving minimal touch, was indicated. The first bodywork session, however, precipitated flashbacks and intrusive thoughts too suddenly and made him feel exposed and vulnerable. This disturbed his psychotherapy and he stopped attending. At this point, the clinician approached him and redirected him to another style of bodywork as a compromise to resume therapy. Breema matched his needs as indicated by continuous weekly sessions for six months, until his symptoms subsided. Meanwhile, the psychotherapist focused on dealing with his flashback and retrieval of his memory in a contained and controlled fashion. According to van der Kolk, it is crucial to help the client retrieve memories in a contained manner. It is counterproductive to push the client to remember more and more, overwhelming the client.

In the case of this client, there were three reasons why Breema was considered more suitable. First, the practitioner was female while his violators had been male. Second, the context was brighter; i.e., the room was well-lit. Third, he was non-threatened by this type of bodywork because the bodyworker was using more direct touch and manipulation of the body, more in concert with his concept of health and healing. In contrast, the Rosen method, a light touch bodywork, was administered in a quiet room with subdued lighting, which made him feel vulnerable and threatened. The combination of Breema and psychotherapy sped the healing process as indicated by the reduction and elimination of the physical symptoms and some of the other PTSD symptoms. His traumatic experience was remembered in a contained fashion that allowed him to make sense of his flashbacks, regain memory of the trauma, make sense of his experience, and learn some sense of mastery of his emotions. He started to sleep better and experienced less anxiety and depression. As his fears diminished, his social functioning improved. The flashbacks and nightmares disappeared, resulting in his renewed interest in a professional career.

Case 2. This case involved two young women relatives who had had similar experiences of torture and persecution. They came to VAST for support and started receiving psychotherapy, followed shortly thereafter by bodywork. Both women received reiki. Their most salient PTSD symptoms were headaches, sleep difficulties, suicide ideation, 
fear, lack of trust, functional impairment, withdrawal, aggressiveness, isolation, and nightmares. Though they had had common experiences of torture and rape, their responses were totally different. One woman demonstrated internalized, passive behaviours while the other demonstrated externalized, aggressive behaviours.

The first woman encountered serious emotional difficulties in communicating with the psychotherapist. Her withdrawal symptoms were so severe that she was closed to any therapy. She was prescribed antidepressants. In contrast, the other young woman made steady progress in psychotherapy and was receptive to the idea of bodywork. As she became more extroverted and receptive to other therapies, whether psychological or bodywork, her results positively influenced her reticent relative.

Eventually, both women participated in bodywork and psychotherapy. Because they had been raped, female psychotherapists and bodyworkers were selected. This combined treatment addressed both the emotional and physical trauma. Reiki, characterized by no direct touch, helped the women accept non-violating, indirect physical contact.

As the internalizing symptoms diminished, the first woman became more responsive to treatment. She eventually became active and engaged in everyday life, demonstrating healthy social functioning. The second one's anger was transformed into positive energy as she became involved in meaningful adult activities - attending school, working, and socializing with others.

Case 3. In working with survivors of torture, the goal often is to alleviate and help the survivor cope with pain. However, in other cases, the goal of complementary therapies may require sensitizing the survivor to respond appropriately to noxious stimuli. A man was receiving therapy from three different professionals. During this process, he was employed in construction work and sustained work-related injuries. His pain signaling system was ineffective in alerting him to significant physical injuries. On one occasion he injured his fingers while hammering boards, but he did not experience any physical pain. It was in the psychotherapeutic context that he was able to recall the trauma of imprisonment and torture. While in prison, he had programmed himself to be numb to the experience of pain during torture. However, now in his country of asylum, this desensitization and underarousal were no longer adaptive, and, in fact, became harmful.

At this point, a reiki bodyworker was recommended. The goal of the bodywork was to sensitize him to feel pain again to promote health, wellness, and safety. The integrated therapy, reiki and psychotherapy, disrupted the desensitization, allowing him to perceive noxious stimuli and experience acute pain. During this period, he rejected recommendations for pain medication. The treatment to his pain, henceforth, was strictly psychotherapy, bodywork, and treatment of physical injuries. Based on the survivor's acute pain, the course of action was massage therapy, reiki, and breathing exercises, known as SIT (stress inoculation training).$^{58}$ The intent of these interventions was to help him learn to respond to pain-producing events. Through each of the therapies, he learned to engage with the painful part of his body, care for the injured part, and do what was necessary to make it feel better. The bodyworkers and the psychotherapist worked in concert to facilitate his efforts to attend to the painful part of his body as if it were a person. Neurological testing of peripheral nerve function would be required to rule out other potential nerve injuries caused by torture for this type of cases.

\section{Discussion}

Practicing complementary therapies necessitates close collaboration and partnership among the survivor of torture, the psychotherapist, and the bodywork practitioner ${ }^{59}$ to respond with sensitivity and care to the survivor's pain, emotional and physical. It is vital to ask for permission from the survivor to see a bodywork practitioner, because the experience of pain is so deeply personal. It is in this context that the psychotherapist and the survivor discuss with the bodywork practitioner the most compatible approach to address individual needs. The psychotherapist, the survivor, and the bodywork practitioner, meanwhile, need to connect, constantly, in an interactive triangle. Feedback from the client and the bodyworker helps in evaluating the body therapy in real time as in the three cases cited.

An important focus of bodywork is how and whether the body therapy affects emotional states. Clinicians need to be alert to the complex nature of pain during body therapy and its effects on physical and psychological recovery. "Knowing what one feels and allowing oneself to experience uncomfortable sensations is essential in planning how to cope with these sensations and emotions." ${ }^{60}$ Hence, it is essential to maintain that interactive triangle through open and constant communication among the psychotherapist, the client, and the bodyworker.

The practice of complementary therapies entails a teaching process in which the survivor needs to learn how to deal with the injured part of his body in a sensitive and caring manner. In Case 3, this was done by sensitizing him to feel pain, to acknowledge it, and to give it the necessary attention - whether it was rest, cold compresses, heat applications, or massaging to treat the pain. "Patients need to develop an internal locus of control by understanding and managing uncomfortable sensations and emotions and by learning effective plans of actions." ${ }^{61}$ For this survivor of 
torture, the learning process required attending to his injuries. In particular, it required providing gentle attention to his physiological and psychological needs, to the whole person, which, ultimately, promoted healing for him.

Although complementary therapies have had a positive effect on survivors of torture, there are some continuing challenges. Treatment tends to be terminated once survivors regain a manageable level of social functioning for two understandable reasons. First, refugees commonly struggle with resettlement and integration into the host country. Commonly, after gaining employment, they stop the therapy. Second, survivors of torture come from cultural or religious backgrounds anchored in an ethos of suffering and endurance of suffering. Once the therapies help them get hold of their symptoms, they feel any residual suffering must be endured. It is, however, impaired social functioning, whether family related or work related, that leads them to resume therapy.

Another challenge is accessibility to services as well as awareness by medical professionals of patient exposure to torture. The study by Eisenman et $\mathrm{al}^{62}$ revealed that none of the 121 participants, survivors of torture, had been identified by primary care physicians. Thus, even if and where these services may be available, many survivors may go untreated. A less discussed issue is the understandable suspicion survivors may experience towards health professionals, when other professionals in their homeland may have participated in the torture. In addition to doctors, other health providers may be unfamiliar with health problems and proper treatment of survivors of torture. Trust and empathy by advocacy organizations, if available, may be the link to potential treatment.

Last, for survivors exiled in developing countries without a reliable medical system, complementary therapies may pose an attractive option in which a traditional healer can serve a dual role of psychotherapist and bodyworker. Though the cultural dimension plays an important role at VAST, that is the topic of another piece.

\section{Conclusion}

This essay is based on clinical experience in controlled circumstances. Thus, more research is needed with recognition of uniqueness of circumstances for each refugee. Nevertheless, this piece offers a set of options for serving survivors of torture coming from particular circumstances supporting the premise that complementary therapies can attenuate the psychological and physical scars inflicted by torture. This model appears to facilitate faster recovery and healing with significant consequences for survivors. Though more research is needed to explore optimum care and interventions for survivors of torture, includingtheapproachpresented in this essay, complementary therapies may allow the "speechless terror" 63 imprinted at the cellular level to emerge and give voice to the trauma in a safe and nurturing environment. Foa and Cahill explicate: "[T] he knowledge of how to treat chronic PTSD by far exceeds the knowledge about when treatment succeeds and when it fails....Very little is known about matching treatments to patients." ${ }^{4}$ Alleviating the psychological and physiological impact of war, trauma, and torture, as well as the reconstruction of the cultural milieu, through complementary therapies are the guiding ethical principles for VAST and for the authors.

\section{Notes}

1. J.D. Kinzie, J. Boehnlein and W. H. Sack "The Effects of Massive Trauma on Cambodian Parents and Children" in Y. Danieli (Ed.), International Handbook of Multigenerational Legacies of Trauma (New York: Plenum Press, 1998) 211-18; W. M. deVries "Trauma in Cultural Perspective" in B. van der Kolk, A. C. McFarlane, and L. Weisaeth (Eds.), Traumatic Stress: The Effects of Overwhelming Experience on Mind, Body, and Society (New York: The Guilford Press, 1996) 398-413; S. W. Turner, A. C. McFarlane and B. van der Kolk "The Therapeutic Environment and New Explorations in the Treatment of Posttraumatic Stress Disorder" in B. van der Kolk, A. C. McFarlane, and L. Weisaeth (Eds.), Traumatic Stress: The Effects of Overwhelming Experience on Mind, Body, and Society (New York: The Guilford Press, 1996) 537-58; M. Eisenbruch "From Post-Traumatic Stress Disorder to Cultural Bereavement: Diagnosis of Southeast Asian Refugees" Social Science \& Medicine, 33 (1991): 673-80; and J. Barudy "A Programme of Mental Health for Political Refugees: Dealing with the Invisible Pain of Political Exile" Social Science and Medicine, 28 (1989): 715-27.

2. R. Yehuda (Ed.) Treating Trauma Survivors with PTSD (Washington, D.C.: American Psychiatric Publishing, Inc., 2002); R. Yehuda, J. Schmeidler, A. Elkin, S. Wilson, L. Siever, K. Binder-Brynes, M. Wainber, and D. Aferiot "Phenomenology and Psychobiology of the Intergenerational Response to Trauma" in Y. Danieli (Ed.), International Handbook of Multigenerational Legacies of Trauma (pp. 639-56). New York: Plenum Press, 1998); E. Gerrity, T. M. Keane and F. Tuma (Eds.) The Mental Health Consequences of Torture (New York: Kluwer Academic/Plenum Publishers, 2001); S. Graessner, N. Gurris, and C. Pross (Eds.), translated by J. M. Riemer At the Side of Torture Survivors: Treating a Terrible Assault on Human Dignity (Baltimore: The Johns Hopkins University Press, 2001); J. M. Jaranson and M. K. Popkin (Eds.) Caring for Victims of Torture (Washington, D.C.: American Psychiatric Press, 1998); and, Y. Danieli International Handbook of Multigenerational Legacies of Trauma (New York: Plenum Press, 1998); M. Thernstrom "Pain, the Disease: When Chronic Suffering is More than a Symptom. New York Times (The New York Times Magazine, December, 16, 2001) 68-71. 
3. International Rehabilitation Council for Torture Victims "Facts about torture", <http://www.irct.org/about_the_irct/ torture.htm>, Accessed 3 February 2002.

4. A. Moreno and M. A. Grodin "Torture and its neurological sequelae" Spinal Cord, 40 (2002): 213-23.

5. Armis \& Prip "Physiotherapy for torture victims (I)," Torture, 10, 73-76 (2000a); and, A. Thomsen, J. Eriksen and K. SmidtNielsen "Chronic pain in torture survivors" Forensic Science International, 108 (2000):155-63.

6. M. Ommeren, J. T. V. M. de Jong, B. Sharma, I. Komproe, S. B. Thapa, and E, Cardena "Psychiatric Disorders Among Tortured Bhutanese Refugees in Nepal” Archives of General Psychiatry, 58 (May 2001): 475-84; Thomsen et al.; and, D. Forrest "The Physical After-Effects of Torture" Forensic Science International, 76 (1995): 77-84.

7. K. Amris and K. Prip "Physiotherapy for torture victims (I)" Torture, 10 (2000a): 73-76; K. Amris and K. Prip "Physiotherapy for torture victims (II)" Torture, 10 (2000b): 112-16; Forrest; and, Thomsen et al.

8. N. Belton The Good Listener: Helen Bamber, a Life Against Cruelty (New York: Pantheon Books, 1998).

9. S. J. Suomi, and S. Levine "Psychobiology of Intergenerational Effects of Trauma: Evidence from Animal Studies" in Y. Danieli (Ed.), International Handbook of Multigenerational Legacies of Trauma (New York: Plenum Press, 1998) 623-38; and, Yehuda Treating Trauma Survivors with PTSD.

10. C. J. Woolf and M. W. Salter "Neuronal plasticity: Increasing the gain in pain" Science, 288 (2000):1765-68.

11. T. Coderre and J. Katz "Peripheral and central hyperexcitability: Differential signs and symptoms in persistent pain"Behavioral and Brain Sciences, 20 (1997): 404-19; and Woolf and Salter "Neuronal plasticity: Increasing the gain in pain".

12. F. Keefe, M. Jacobs, and L. Underwood-Gordon "Biobehavioral pain research: a multi-institute assessment of cross-cutting issues and research needs" Clinical Journal of Pain, 13 (1997):91-103; and Woolf and Salter "Neuronal plasticity: Increasing the gain in pain".

13. Keefe et al.

14. H. Merskey and N. Bogduk Classification of Chronic Pain: Descriptions of Chronic Pain Syndromes and Definition of Pain Terms, $2^{\text {nd }}$ ed. (Seattle: IASP Press, 1994).

15. W. E. Fordyce "Pain and suffering: A reappraisal" American Psychologist, 43 (1988): 276-83.

16. Ibid.

17. Ibid.

18. Ibid.

19. L. B. Ready and W. T. Edwards Management of Acute Pain: A Practical Guide (Seattle: IASP Press, 1992).

20. Merskey, H. and Bogduk, N. Classification of Chronic Pain: Descriptions of Chronic Pain Syndromes and Definition of Pain Terms, $2^{\text {nd }}$ ed.,(Seattle: IASP Press, 1994).

21. R. Dubner "Neural Basis of Persistent Pain: Sensory specialization, sensory modulation, and neuronal plasticity" in $\mathrm{T}$. Jensen, J. Turner, and Z. Wiesenfeld-Hallin (Eds.), Proceedings of the $8^{\text {th }}$ World Congress on Pain, Progress in Pain Research and Management Seattle: IASP Press, 1997) 243-57.

22. Ibid.

23. Ibid.

24. Ready and Edwards, 4.

25. Woolf and Salter.

26. D. Price, J. Mao, and D. Mayer "Central consequences of persistent pain states" in T. Jensen, J. Turner, and Z. Wiesenfeld-Hallin (Eds.), Proceedings of the $8^{\text {th }}$ World Congress on Pain, Progress in Pain Research and Management (Seattle, WA: IASP Press, 1997) 8:155-84; and, Woolf and Salter.

27. Dubner.

28. J. M. Besson "The neurobiology of pain" Lancet, 353 (1997): 1610-15; and Merskey and Bogduk.

29. T. Coderre, J. Katz, A. Vaccarino and R. Melzack "Contribution of central neuroplasticity to pathological pain: review of clinical and experimental evidence. Pain, 52 (1993): 259-85; P. Siddall and M. Cousins, "Neurobiology of Pain," International Anesthesiology Clinics, 35 (1997): 1-26; and Dubner.

30. Coderre et al.; and, Siddall and Cousins.

31. C. J. Woolf and M. B. Max "Mechanism-based pain diagnosis: Issues for analgesic drug development" Anesthesiology, 95 (2001): 241-49; and, Woolf \& Salter.

32. R. Melzack and P. D. Wall "Pain Mechanisms: a New Theory" Science, 150 (1965): 971-79; and Price, D., Psychological Mechanisms of Pain and Analgesia, (Seattle: IASP Press 1999).

33. Dubner.

34. Examples of inhibitory neurotransmitter are GABA, glycine, endogoneous opioids, serotinin, and noradrenaline.

35. Supraspinal structures include the hypothalamus, periaqueductal gray matter, locus coeruleus, and nucleus raphe magnus.

36. Dubner; and, Siddall and Cousins.

37. L. Jacobsen and K. Smidt-Neilsen Torture Survivor-Trauma and Rehabilitation (Copenhagen: International Rehabilitation Council for Torture Victims (IRCT), 1997).

38. A. Y. Shalev "Treating Survivors in the Immediate Aftermath of Traumatic Events" in R. Yehuda (Ed.), Treating Trauma Survivors with PTSD (Washington, D.C.: American Psychiatric Publishing, 2002) 157-88; S. Bøjholm and P. Vesti "Multidisciplinary Approach in the Treatment of Torture" in M. Bapoðlu (Ed.), Torture and its Consequences: Current Treatment Approaches (pp. 299-309). Cambridge: University Press, 1992) 299-309; and Jaranson and Popkin.

39. Bøjholm and Vesti.

40. E. B. Foa and S. P. Cahill "Specialized Treatment for PTSD: Matching Survivors to the Appropriate Modality" in R. Yehuda (Ed.), Treating Trauma Survivors with PTSD (Washington, D.C.: American Psychiatric Publishing, 2002) 43-62; B. van der Kolk "Assessment and Treatment of Complex PTSD" in Rachel Yehuda (Ed.), Treating Trauma Survivors with PTSD (Washington, D.C.: American Psychiatric Publishing, 2002) 127-56; B. Rothschild The Body Remembers: The Psychophysiology of Trauma and Trauma Treatment (New York: W. W. Norton \& Company, 2000); M. Esfandiari and F. 
MacQueen “The Vitality of Interconnectedness: VAST's Service Delivery Programme, First Alone, Then Together" Refuge, 18, No. 3, (2000): 50-55; A. J. Marsella, M. J. Friedman and E. H. Spain "A Selective Review of the Literature on Ethnocultural Aspects of PTSD”. PTSD Research Quarterly, 3 (1992): 1-8.

41. A. E. Taylor, Keynote Speech, Refugee Mental Health Conference, Vancouver, B.C., Canada, October 2002.

42. World Confederation for Physical Therapy "Declarations of Principle and Position Statements" (United Kingdom: WCPT Secretariat, July1997).

43. Amris and Prip "Psysiotherapy for Torture Victims (I)"; Amris and Prip "Psysiotherapy for Torture Victims (II)"; and, K. Prip, L. Tived and N. Holten, Physiotherapy for Torture Survivors: A Basic Introduction (Copenhagen: International Rehabilitation Council for Torture Victims (IRCT), 1995).

44. American Physical Therapy Association, Guide to Physical Therapy Practice, $2^{\text {nd }}$ ed., Physical Therapy 81 (2001): 9-744.

45. World Health Organization "International classification of Functioning and Disability (January 2002)", <http://www. who.int/m/topics/icf/en/index.ht ml >. Accessed 3 April 2002.

46. Amris and Prip "Physiotherapy for Torture Victims (I)"; and, Amris and Prip "Physiotherapy for Torture Victims (II)".

47. Ibid.

48. Amris and Prip "Psysiotherapy for Torture Victims (I)", 112.

49. Amris and Prip "Physiotherapy for Torture Victims (II);" and Bøjholm and Vesti.

50. E. T. Peuker, A. White, E. Ernst, F. Pera, and T. J. Filler "Traumatic Complications of Acupuncture" Archives of Family Medicine, 8 (1999): 553-58; and, A. Bensoussan, S. P. Myers, and A-L. Carlton "Risks Associated With the Practice of Traditional Medicine" Archives of Family Medicine, 9 (2000): 1071-78.

51. L. Nasir "Acupuncture in a University Hospital" Archives of Family Medicine, 7 (1998): 593-96.

52. "Glossary of some of the methods used by some of the Volunteer Bodywork Practitioners at VAST" VAST Quarterly, 2 (June 2001): 6-7 at 7.

53. Ibid., 7.

54. J. Arnold “Alexander Technique" http://alexandertechnique.com/at/, Accessed 1 December 2002; R. Brennan "What is the Alexander Technique?", http://alexandertechnique. com/articles/brennan, Accessed 1 December 2002; J. Chance "Principles of the Alexander Technique" in J. Chance, The Alexander Technique (<http://alexandertechnique.com/articles/chance $>$. Accessed 1 December 2002).

55. "What is the Alexander Technique" <http://alexandertechnique.com/at.htm>. Accessed 1 December 2002.

56. "Glossary of some of the methods used by some of the Volunteer Bodywork Practitioners at VAST" at 6.

57. Ibid.

58. Foa and Cahill, at 50.

59. Esfandiari and MacQueen.

60. Van der Kolk, at 143.

61. Ibid.
62. D. P. Eisenman, A. S. Keller and G. Kim "Survivors of torture in a general medical setting: how often have patients been tortured, and how often is it missed?" Western Journal of Medicine, 172 (2000): 301-4.

63. Van der Kolk.

64. Foa and Calhill, at 48 and 49.

Claudia María Vargas is a research assistant professor, Department of Pediatrics, and Director of Intercultural Programs, Vermont Interdisciplinary Leadership Education for Health Professionals Program, University of Vermont.

Deborah O'Rourke is an assistant professor in the Department of Physical Therapy, College of Nursing and Health Sciences, at the University of Vermont in Burlington, Vermont.

Mahshid Esfandiari, Ph.D., R.C.C., is a clinical psychologist, the clinical coordinator at Vancouver Association for the Survivors of Torture (VAST), and a Registered Clinical Counsellor with the Employee \& Family Assistance Program (EFAP) team in British Columbia. The authors are grateful to Ms. Francis McQueen, Coordinator, Vancouver Association for the Survivors of Torture, for her feedback and critical readings of the manuscript. 